\title{
DESTRUIÇÃO E MORTE: FRAGMENTOS DE UM MOSAICO COMPOSICIONAL EM THE SANDMAN, DE NEIL GAIMAN
}

\section{DESTRUCTION AND DEATH: FRAGMENTS OF A COMPOSITIONAL PUZZLE IN THE SANDMAN, BY NEIL GAIMAN}

\author{
Willian André ${ }^{*}$ \\ UNESPAR

\section{Cleverson de Lima** \\ UNESPAR/UEL}

Resumo: Este estudo tem por objetivo contemplar dois episódios específicos da graphic novel The Sandman, de Neil Gaiman, publicados respectivamente nos arcos intitulados Brief lives e The Kindly Ones. Tais episódios mostram-se de primeira importância para o desfecho de The Sandman, que culmina na morte de seu protagonista, Sonho, permitindo-nos refletir sobre a atitude suicida do personagem. A exemplo do mosaico de referências que constitui a graphic novel estudada, a presente leitura se desenvolve também na forma de um mosaico composicional, procurando destacar várias possibilidades de abordagem que se complementam na análise/compreensão da obra: a condição híbrida visível no esboroamento das fronteiras entre narrativa literária e história em quadrinhos; as referências intertextuais; aspectos consonantes com a caracterização da literatura pós-moderna, entre outras.

Palavras-Chave: The Sandman; graphic novel; intertextualidade.

\begin{abstract}
This study aims at contemplating two specific episodes in the graphic novel The Sandman, by Neil Gaiman, respectively published in the arcs Brief lives and The Kindly Ones. Such episodes are of major importance for the closure of The Sandman, which culminates with the death of its protagonist, Dream, allowing us to think about the suicide attitude of the character. Following the pattern of a referential puzzle that constitutes the graphic novel, our reading is also developed under the structure of a compositional puzzle, highlighting several possibilities of approach that fulfill each other in the analysis/comprehension of the work: the hybrid condition observable in the blurring of boundaries between literary narrative and comics; the intertextual references; aspects that are consonant with the characteristics of postmodern literature, among others.
\end{abstract}

Keywords: The Sandman; graphic novel; intertextuality.

\author{
*Professor Adjunto \\ no Colegiado \\ de Letras da \\ UNESPAR/Campo \\ Mourão. Doutor \\ em Letras-Estudos \\ Literários (2016) \\ pela UEL. Contato: \\ willianandreh@ \\ hotmail.com. \\ ${ }^{* *}$ Mestre em \\ Sociedade e \\ Desenvolvimento \\ (2017) pela \\ UNESPAR/Campo \\ Mourão. Mestrando \\ em Comunicação \\ pela UEL. Contato: \\ cleverson@ \\ oxycreative.com.br.
}


"Não se pode procurar Destruição e voltar ileso" Desespero dos Perpétuos (Neil Gaiman)

The Sandman foi uma graphic novel publicada originalmente por Neil Gaiman, em edições mensais, entre 1989 e 1996. Ao longo de seus 75 volumes, encontramos a história dos Perpétuos: sete irmãos que representam aspectos diversos da jornada humana sobre a Terra: Sonho, Morte, Destruição, Destino, Desejo, Desespero e Delírio ${ }^{1}$. Para muito além de qualquer tipo de alegoria, tais personagens carregam, em sua constituição, aspectos de deuses, cada um possuidor de seu próprio reino, e donos de poderes que influenciam diretamente as vidas dos seres humanos. Ao mesmo tempo, todavia - e nem poderia ser diferente -, eles próprios também são, por diversas vezes, demasiadamente humanos - principalmente Sonho, o protagonista da narrativa -, o que evidencia, em termos generalizantes, as trocas sempre existentes entre imaginário simbólico e práticas cotidianas que caracterizam a condição humana.

Ao nomearmos The Sandman como graphic novel, não perdermos de vista que se trata, em última instância, de uma história em quadrinhos - formato que, em seu histórico, já enfrentou muitos preconceitos (notadamente na esfera acadêmica), mas que hoje goza de algum prestígio, principalmente devido ao esforço pioneiro de Will Eisner na sistematização de estudos consistentes a respeito. A Eisner coube, por exemplo, estabelecer o entendimento de que a narrativa sequencial em quadros consiste em uma forma de linguagem muito particular e complexa, e desenvolver tanto um vocabulário quanto conceitos específicos para se pensar essa manifestação artística em termos mais teóricos:

Em seu estado mais econômico, quadrinhos empregam uma série de imagens repetitivas e símbolos reconhecíveis. Quando estes são usados constantemente para transmitir ideias similares, eles se tornam uma linguagem - uma forma literária, se se quiser. E é essa aplicação disciplinada que cria a "gramática" da arte sequencial (EISNER, 1985, p. 8, tradução nossa).

Realizar aqui, todavia, um levantamento e discussão dos muitos trabalhos que ecoam e desenvolvem os esforços iniciais de Will Eisner é tarefa que nos distanciaria de nosso principal objetivo: neste estudo, tentamos realizar uma leitura de The Sandman, propondo um recorte que contempla dois episódios específicos da graphic novel, e que apresentam informações de primeira importância para a compreensão de seu trágico desfecho. Segundo nossa interpretação, ainda que não tenha cometido explicitamente um ato violento contra sua própria existência, determinadas decisões e atitudes de Sonho permitem que compreendamos sua conduta como a de um suicida. A fim de construir uma análise que possa sustentar tal argumento, transitaremos livremente por diferentes possibilidades de abordagem dos dois recortes
${ }^{1}$ No original, em inglês, os nomes dos Perpétuos (The Endless) são, respectivamente: Dream, Death, Destruction, Destiny, Desire, Despair e Delirium. 
narrativos selecionados, denunciando em nossa própria prática o mesmo caráter multifacetado que rege a composição de nosso objeto de estudo.

O primeiro episódio de que trataremos é narrado no arco Brief lives (em português, "Vidas breves”). Há algum tempo (não determinado), Destruição, um dos membros da família dos Perpétuos, está desaparecido. A irmã mais nova, Delírio, decide partir em sua procura, e pede a ajuda dos demais na empreitada. O único que decide ajudá-la é Sonho. O episódio em questão consiste, portanto, nessa busca por Destruição.

Consequência direta dos acontecimentos apresentados em Brief lives, o segundo episódio a ser contemplado é relatado no arco The Kindly Ones (que, no Brasil, foi traduzido como "Entes queridos”). Penúltimo arco a compor o desenvolvimento narrativo de The Sandman, The Kindly Ones é aquele que apresenta o desfecho da graphic novel ${ }^{2}$. Suas páginas mostram Sonho sendo perseguido pelas Erínias - personagens originalmente pertencentes à mitologia grega, responsáveis por vingar crimes de sangue -, e o encontro final entre o protagonista e Morte, sua irmã.

Antes de iniciarmos a exploração desses dois episódios, a primeira consideração que gostaríamos de fazer diz respeito à pertinência de se abordar The Sandman com base nas teorias do fantástico. Não apenas nos dois recortes que analisaremos, mas na graphic novel como um todo, Gaiman propõe um flerte constante com elementos que podemos chamar, genericamente, de “sobrenaturais”. Já observamos, acima, que os personagens ao redor dos quais o enredo se constrói se assemelham a deuses. Isso gera uma associação quase imediata com as estruturas composicionais de mitologias diversas. E, de fato, Gaiman apresenta como personagens secundários de sua narrativa deuses e entidades provenientes, entre outras, das mitologias grega, escandinava, africana e egípcia, além de figuras proeminentes no imaginário cristão, como Lúcifer, Caim e Abel.

Todavia, tais personagens são deslocados de seus contextos originais, e recebem novas roupagens (por vezes, bastante inusitadas), sendo inseridos no contexto vivido pelo próprio autor à época da composição da graphic novel: as duas últimas décadas do século 20 - como se Gaiman estivesse a erigir uma espécie de “mitologia moderna”. Portanto, o que encontramos em The Sandman é a intromissão de seres e acontecimentos sobrenaturais, impossíveis de serem explicados de um ponto de vista racional, em um contexto que, a princípio, se supunha regido pela racionalidade. É nesse sentido que se constrói um diálogo permanente entre a obra e as teorias do fantástico.

Ao pensarmos em tais teorias, acodem-nos à mente, de partida, estudiosos que foram pioneiros no desenvolvimento dessa faceta da teoria literária - em especial Tzvetan Todorov, autor de Introdução à teoria fantástica. Todorov, no entanto, se concentrou principalmente sobre as manifestações do fantástico na produção literária do século 19. Nesse sentido,

\footnotetext{
${ }^{2} \mathrm{O}$ último arco, Awakening ("Despertar"), atua muito mais como uma espécie de “epílogo” para a obra.
} 
para que possamos realizar uma abordagem mais profícua da graphic novel de Gaiman a partir dessa abordagem, podemos recorrer a autores que ofereceram desdobramentos a suas reflexões iniciais, deitando olhos sobre a literatura do século 20. David Roas, por exemplo, apresenta, no primeiro capítulo da obra Teorías de lo fantástico, intitulado La amenaza de lo fantástico, a seguinte reflexão:

Basado (...) en la confrontación de lo sobrenatural y lo real dentro de un mundo ordenado y estable como pretende ser el nuestro, el relato fantástico provoca - y, por tanto, refleja - la incertidumbre en la percepción de la realidad diferente a la nuestra, conduce, por un lado, a dudar acerca de esta última y, por otro, y en directa relación con ello, a la duda acerca de nuestra propria existencia: lo irreal pasa a ser concebido como real, y lo real, como posible irrealidad. Así, la literatura fantástica nos descubre la falta de validez absoluta de lo racional y la possibilidad de la existencia, bajo esa realidad estable y delimitada por la razón en la que habitamos, de una realidad diferente e incomprensible, y, por lo tanto, ajena a esa lógica racional que garantiza nuestra seguridad y nuestra tranquilidad. En definitiva, la literatura fantástica pone de manifesto la relativa validez del conocimiento racional al iluminar una zona de lo humano donde la razón está condenada a fracasar (ROAS, 2001, p. 9).

Conforme Roas, portanto, o elemento sobrenatural, ou fantástico, atua nesse tipo de narrativa como uma espécie de ameaça: uma de suas principais funções é desestabilizar os conhecimentos instituídos e as certezas que os discursos racional e científico imprimem às práticas cotidianas. Esse processo de “desestabilização” é uma constante em The Sandman. Por isso, ainda que nossa proposta, aqui, não seja realizar uma leitura da obra à luz das teorias do fantástico, julgamos que qualquer análise dela que se possa desenvolver deve sempre considerar esse aspecto. Ainda que não recuperemos, doravante, reflexões de teor semelhante, partimos para a leitura de nossos dois recortes narrativos específicos tendo em mente que o questionamento da "validade absoluta do racional”, bem como a instauração da "possibilidade da existência (...) de uma realidade diferente e incompreensível”, é uma das premissas básicas a reger a composição de The Sandman.

Outra constante ao longo de toda a graphic novel diz respeito a um quadro de aspectos que nos permitem aproximá-la das características que parte da crítica tem reunido, desde as últimas décadas do século 20 , sob a expressão “literatura pós-moderna”. Uma das principais entre essas características é a fragmentação. Esta diz respeito à crescente impossibilidade de se compreender o indivíduo como um todo homogêneo, coeso. Em vez disso, assume-se a consciência de que possuímos identidades multifacetadas - e, por consequência, nossa experiência com o mundo, a forma como o compreendemos, também acaba sendo atingida por essa impressão de fragmentação. Segundo Linda Hutcheon, “Já não se presume que o indivíduo perceptor 
seja uma identidade coerente, geradora de significados” (HUTCHEON, 1991, p. 29). E Nízia Villaça pontua a dissolução de uma individualidade "capaz de representar, ou seja, de lançar a ponte bem alicerçada da verdade em direção ao objeto” (VILLAÇA, 1996, p. 34).

Em The Sandman, esse processo pode ser observado em pelo menos dois níveis. O primeiro deles é a fragmentação da narrativa. Além de diversos sub-enredos que vão se misturando à história principal, a narrativa não se desenvolve seguindo uma linearidade cronológica: ora se desloca para o passado, ora para o futuro, apresentando sempre episódios fragmentados. Esse procedimento parece consequência de um nível mais profundo de fragmentação, que é o da identidade dos personagens apresentados. Principalmente no protagonista, Sonho, mas também em alguns personagens secundários, é possível identificar características como aquelas delineadas por Hutcheon: "Na ficção os narradores passam a ser perturbadoramente múltiplos e difíceis de localizar (...), ou deliberadamente provisórios e limitados” (HUTCHEON, 1991, p. 29); ou por Tânia Pellegrini: "uma subjetividade voltada sobre si mesma, ancorada na descrição de estados de ânimo difusos e inconsistentes, de alucinações e sensações indefinidas” (PELLEGRINI, 1994, p. 55). Ambos os trechos parecem apontar para uma espécie de "crise de identidade”, que define em bons termos a caracterização de Sonho.

Com relação à fragmentação narrativa, esta pode ser observada desde os títulos escolhidos por Gaiman para os capítulos em que se subdivide o arco Brief lives. No total, são nove capítulos. Cada um dos nove títulos é composto por uma série de expressões, referentes aos acontecimentos que serão relatados. Observemos, por exemplo, o título do capítulo 2: “Dois: sempre chove sobre os desprezados - sonhos molhados - uma pescaria - ela beija Wyvern (analogia da Disneylândia) - jantares, etiqueta e chocolate - Desejo jura pelo primeiro círculo - ‘as coisas estão mudando' - o que poderia dar errado?” (GAIMAN, 2007, p. 39). O título se estende por três linhas a fio, e é composto por uma série de fragmentos que não possuem, necessariamente, relações diretas uns com os outros.

O título Brief lives constitui uma referência bem delimitada. Logo na página inicial do arco, há uma epígrafe, que consiste em palavras de John Aubrey: "Ele ainda estava deitado, perdido na agonia da morte, quando os passantes o ouviram dizer baixinho: eu vi todas as glórias do mundo” (GAIMAN, 2007, p. 1). Aubrey foi um autor inglês que viveu no século 17, e que ficou conhecido principalmente por suas Brief lives - uma coleção de pequenas peças biográficas, polêmica por conter informações um tanto constrangedoras e imprecisas a respeito das vidas dos biografados. Minutes for lives, título que aparece na epígrafe de Gaiman, foi um dos títulos provisórios dados pelo autor a Brief lives, à época de sua composição.

Além de consistir, em primeira instância, em uma referência intertextual a nível de referência ou citação, a escolha de Gaiman pelo título em 
questão também pode ser compreendida, de maneira mais indireta, como uma referência intertextual de tom parodístico (e a paródia é outra das constantes nas caracterizações da literatura pós-moderna): o autor de The Sandman parece estar declarando, em tom jocoso, que apresentará, nas páginas que seguem a epígrafe, pequenas biografias de seus personagens.

Há, todavia, um aspecto que simultaneamente contradiz esse tom de paródia: o trecho da epígrafe retrata o momento da morte de um indivíduo: “Ele ainda estava deitado, perdido na agonia da morte”. E é justamente em Brief lives que tomam corpo os acontecimentos que culminarão na morte de Sonho. As palavras de Aubrey usadas por Gaiman atuam, portanto, como anunciadoras dos acontecimentos trágicos que estão por vir.

Em última instância: a referência a Aubrey evidencia a utilização, na composição de The Sandman, de autores consagrados ou canônicos. Referências desse tipo podem ser encontradas ao longo de todos os 75 volumes que constituem a graphic novel. Se considerarmos que, no título do capítulo 2 de Brief lives, transcrito poucas linhas acima, encontramos a palavra "Disneylândia”, chegamos a outro dos procedimentos constantemente empregados por Gaiman - procedimento que novamente aponta para as caracterizações da literatura pós-moderna: a diluição das fronteiras entre as culturas popular e erudita. Elementos pertencentes a ambas as esferas se misturam com frequência no enredo de The Sandman.

Já observamos que o desenvolvimento narrativo do arco Brief lives gira em torno do convite feito por Delírio a Sonho, para iniciar uma busca por Destruição. O momento que precede diretamente esse convite é emblemático, e deve ser destacado. Sonho está sofrendo uma desilusão amorosa: a humana com quem ele estava se relacionando há algum tempo decidiu deixá-lo. Na primeira página do capítulo 2, uma sequência de quadros apresenta o personagem andando por um quarto escuro, em direção a uma sacada, e dizendo: "Ela... Ela decidiu que não me ama mais” (GAIMAN, 2007, p. 37). Na página seguinte, já na sacada, o personagem aparece sob uma chuva forte, conforme a Imagem 1 , a seguir: 
Imagem 1: Sempre chove sobre os desprezados

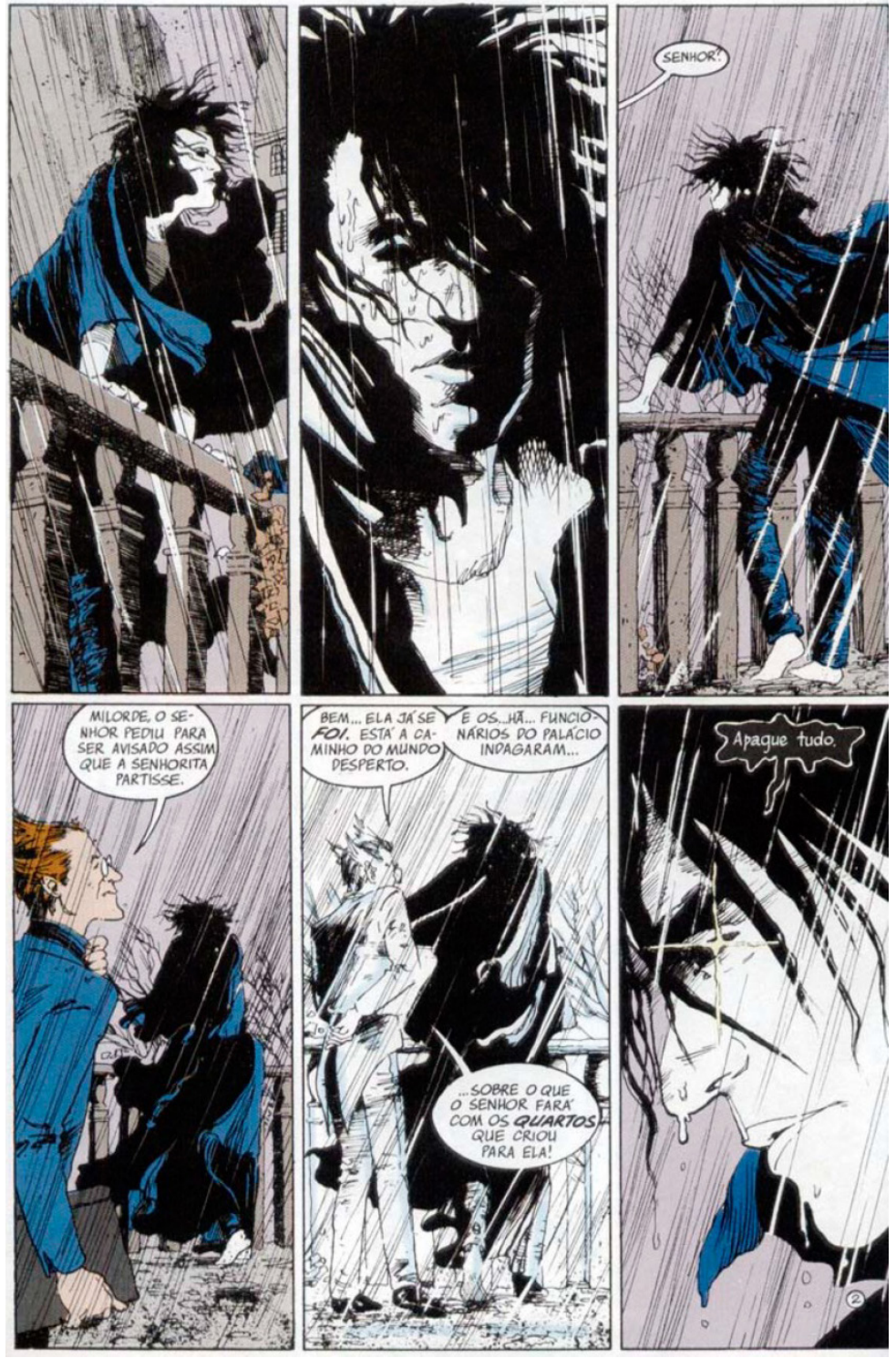

(GAIMAN, 2007, p. 38)

A chuva, aqui, reflete o humor de Sonho: simboliza o estado de tristeza e desânimo advindos de sua decepção. Encontramos, na sequência da imagem reproduzida, referências explícitas a essa transposição do estado de alma do personagem nas condições climáticas que o circundam, como na seguinte fala de Mervyn ${ }^{3}$ :

Ora, diabos. É tudo pose, saca? Ele fica uns meses com uma mina, até acabar a magia. Aí, ele volta pro trabalho, ela leva um pé na bunda. (...) É a

\footnotetext{
${ }^{3}$ Mervyn é uma das muitas figuras inusitadas que aparecem como "funcionários" que trabalham no reino de Sonho, o "Sonhar". Trata-se de um espantalho, que aparece constantemente fumando, e cujas falas são sempre marcadas por um tom coloquial, como podemos perceber no trecho transcrito. Na configuração do "Sonhar”, Gaiman propõe uma inversão no que diz respeito às reflexões sobre o fantástico há pouco esboçadas: o espantalho, uma figura constante em pesadelos, trabalha em um ambiente sobrenatural como se fosse o funcionário de uma empresa. Nesse movimento, podemos observar a inserção de elementos do mundo "real" ou "racional" no mundo onírico.
} 
vida, pô. Tem que engolir essas coisas. Mas ele, não. Ah, não. Ele precisa ser a figura trágica, tomando chuva, chorando a perda da amada. E aí, dá-lhe chuva. Enquanto isso, todo mundo tem sonhos cheios de angústia existencial e acorda um caco. E a gente fica encharcado (GAIMAN, 2007, p. 41).

Passagens como essas evidenciam o caráter fragmentado da identidade de Sonho. Trata-se de um personagem sobre-humano, dono de poderes quase imensuráveis (ao ponto de seu estado de alma, conforme as palavras de Mervyn, influenciarem nos sonhos dos seres humanos). Ao mesmo tempo, todavia, a imagem de um indivíduo angustiado com o fim abrupto de uma relação amorosa é uma das coisas mais humanas que se pode conceber. As figuras do deus e do sujeito ordinário misturam-se, como fragmentos, na composição de sua identidade.

Além disso, a imagem da chuva como reflexo do estado de alma do personagem dá ao texto um tom consideravelmente poético, o que sugere um trabalho cuidadoso na articulação entre texto escrito e texto imagético para a composição da obra. Em teoria literária, tratando-se do gênero lírico, é recorrente a concepção do espaço enquanto projeção da interioridade do eu lírico. Na sequência de quadros reproduzida acima, a imagem é agregada à palavra escrita justamente para produzir tal efeito, gerando um híbrido entre história em quadrinhos e poesia. Esse processo reflete o trabalho crítico na composição de uma graphic novel:

A gramática da narrativa visual exige que o autor reflita criticamente sobre como quer contar a história (...). Em graphic novels que empregam palavras, a ênfase na linguagem não é deslocada pela ênfase na imagem, mas ambas são combinadas pelo autor de modo a mostrar a interdependência entre imagem e texto (KELLEY, 2010, p. 3, tradução nossa).

O mesmo efeito pode ser constatado algumas páginas depois. Diante da visita inesperada de Delírio, Sonho convida-a para jantar. Ao ser questionada sobre o que deseja comer, talvez por tratar-se de uma personagem sempre caracterizada como excêntrica, e também por encontrar-se em um ambiente onírico, Delírio responde: “Tem pessoinhas de chocolate ao leite? Assim, com uns oito centímetros? Homens e mulheres? Quero isso. Com recheio de creme de framboesa” (GAIMAN, 2007, p. 49). Já o pedido de Sonho é extremamente sóbrio - demasiado humano - para alguém que goza de sua condição: "Uma omelete, uma salada leve e um cálice de vinho branco” (GAIMAN, 2007, p. 49). Quando as “pessoinhas de chocolate” são servidas, Delírio, em vez de comê-las, passa a brincar com elas, simulando um beijo entre ambas. Diante dessa imagem, Sonho é afligido por sua desilusão amorosa recente, fica visivelmente irritado, e ambos os personagens acabam deixando a mesa. O último quadro da página que retrata essa cena é focalizado no prato em que estava a comida de Delírio (Imagem 2, a seguir). A descrição oferecida no quadro carrega um tom extremamente poético, e a 
imagem que a acompanha, com os traços dos pequenos seres a confundir-se com o chocolate derretido, colabora para a criação dessa composição lírica:

Imagem 2: As pessoas de chocolate

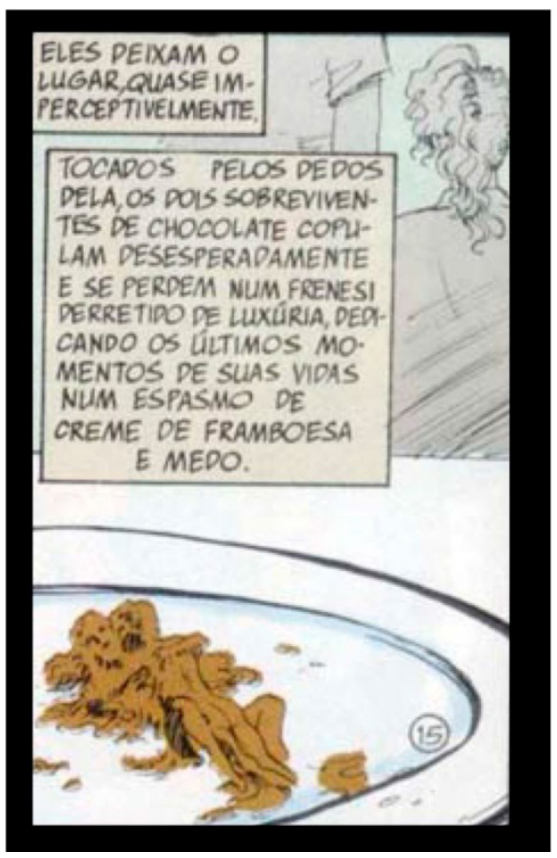

(GAIMAN, 2007, p. 51)

Além disso, o trecho final, “abandonadas a um frenesi derretido de luxúria, dedicando os últimos instantes de sua vida fugaz a um espasmo de creme de framboesa e medo”, estabelece um diálogo direto com o título Brief lives. Em última instância, é possível ainda contrastar o acento lírico da passagem com o tom coloquial da fala de Mervyn, transcrita mais acima, o que evidencia o jogo de vozes de que Gaiman toma mão para a composição de sua narrativa.

Com o objetivo de distrair-se para não pensar em seu coração partido, Sonho aceita a proposta de Delírio, e ambos iniciam uma jornada em busca de Destruição. O enredo de todo o restante de Brief lives apresenta as desventuras dessa busca. Ao longo de suas páginas, encontramos a mistura de referências constantes às culturas popular e erudita: músicas de Tori Amos, Queen, David Bowie, Marvin Gaye e Iggy Pop, ao lado de uma referência ao livro bíblico de Jó, e a escritores como Jonathan Swift e Samuel Taylor Coleridge. Além disso, há pelo menos mais um trecho de extremo lirismo, quando, numa espécie de fluxo de consciência, Sonho adentra os territórios de Delírio: 
uma mulher com pombos nos ombros. os pombos são escorpiões. a mulher é uma poça de sorvete derretendo na calçada num dia quente de verão. dez dias sem dormir cambaleiam e borbulham em sua direção, passam por ele e seguem adiante. o cheiro azedo e clínico de um hospital, trazendo consigo leitos, cirurgiões e soro fisiológico. quartos escuros com pessoas disformes que exalam mortalhas amargas. maçãs mentais ainda verdes rolam gritando pelos céus e as estrelas engasgam em clarões breves de dor e tempo. pútrido o mar oscila em ondas lentas e viscosas e malcheirosas e trêmulas e formas fetais que flutuam e cintilam e gemem. (coloque a arma na boca coloque a arma na boca coloque a arma na boca). o mar é uma princesa de dança incomum. o alienígena é um alienígena. a dança é um beco onde morrem os bebês... (GAIMAN, 2007, p. 161-162).

O trecho se traduz em uma composição de prosa poética, reunindo características que são constantes na estética da lírica moderna, como o efeito de dissonância (cf. FRIEDRICH, 1978, p. 15), e a inapreensibilidade do significado. A partir dele, ressalta-se ainda mais o hibridismo entre narrativa em quadros e poesia levado a cabo por Gaiman.

Já perto do desfecho do arco, a busca nele relatada ainda não cumpriu seu objetivo. Diante da decepção da irmã mais nova, Sonho acaba recorrendo a uma solução radical. Seu filho, Orpheus, é um oráculo, e conhece o paradeiro de Destruição. Há milênios, todavia, pai e filho não trocam palavras ${ }^{4}$. Para que possa descobrir como encontrar o irmão desaparecido, e satisfazer a vontade de Delírio, Sonho decide procurar por Orpheus.

Segundo as narrativas que circundam o mito do personagem, Orfeu foi atacado pelas Bacantes (ou Mênades), que dilaceraram seu corpo, restando dele apenas a cabeça (que prosseguiu viva). Gaiman mantém essa versão em sua releitura. Portanto, ao ir ao encontro do filho, é apenas com a cabeça deste que Sonho se depara - uma cabeça que tem sido preservada, viva, há milênios, em um templo na Grécia (conforme Imagem 3, na seguir):
${ }^{4}$ Orpheus, aqui, é o mesmo personagem mitológico que dispensa apresentações, cujas desventuras amorosas com Eurídice são cantadas por Virgílio nas Geórgicas (IV, 453-527). Em determinada edição de The Sandman, anterior ao arco Brief lives, Gaiman apresenta uma releitura desse episódio. Em sua versão, Sonho (também chamado, naquele contexto, de Oneiros) é o pai de Orfeu. Após o incidente no Hades e a perda definitiva de Eurídice, Sonho não aceita a reclusão e sofrimento em que seu filho acaba mergulhando. Por conta disso, ambos têm uma briga, e se separam. 
Imagem 3: a cabeça de Orpheus

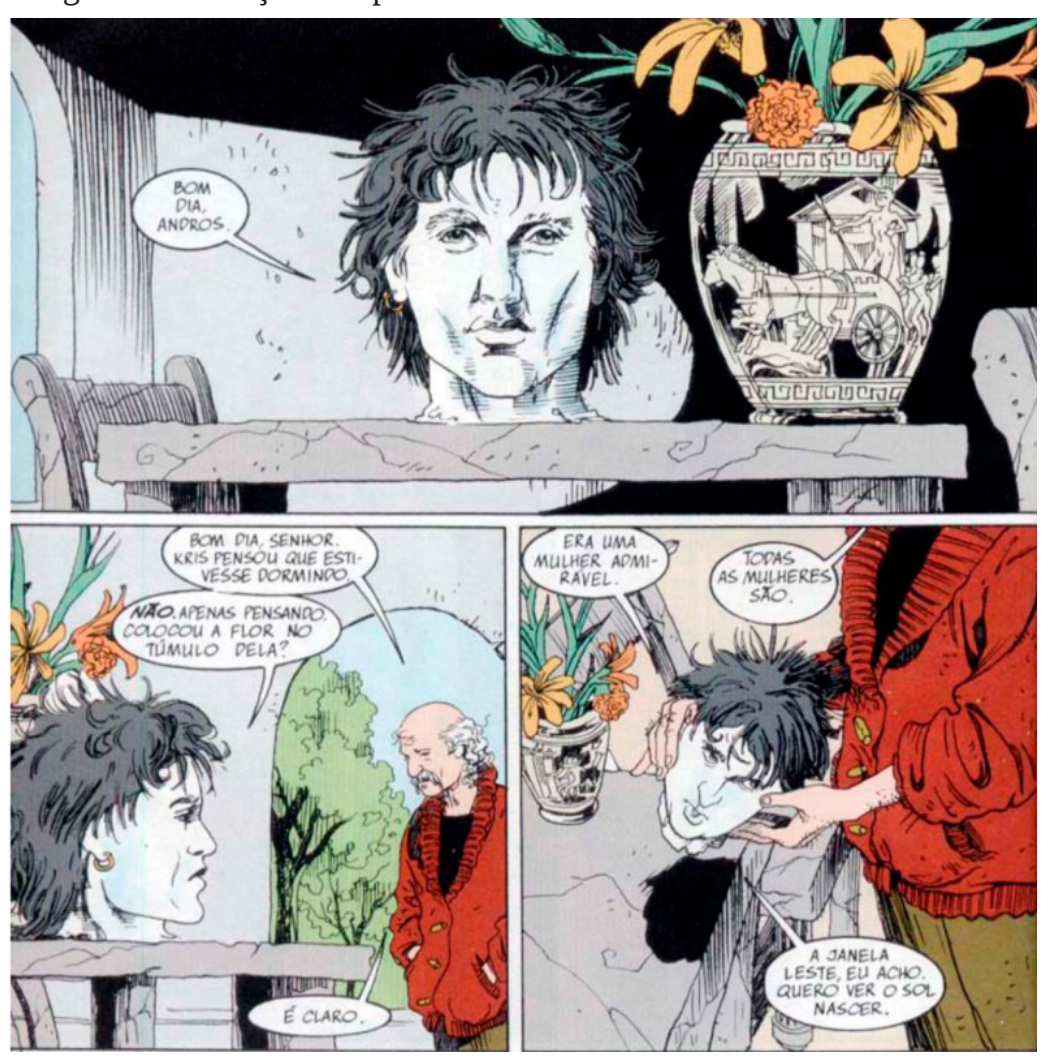

(GAIMAN, 2007, p. 14)

Conforme mostram as imagens na sequência de quadros acima, apesar do tom resignado de suas palavras, o personagem tem sustentado uma existência milenar de solidão e privação - já que depende de auxílio para realizar qualquer tipo de movimento. Quando Sonho vem à sua procura e lhe pede um favor, Orpheus propõe uma troca: ele ajudará seu pai a encontrar Destruição, desde que este concorde em pôr um fim a seus dias, dando-lhe, finalmente, descanso. Sonho aceita realizar a troca. O encontro com Destruição é cumprido. Os três irmãos passam uma noite juntos, comem do banquete preparado pelo anfitrião, e depois se despedem. Para cumprir sua parte do acordo, Sonho volta ao templo que guarda a cabeça de Orpheus, e mata seu próprio filho. A imagem apresentada logo na sequência reúne, uma vez mais, uma composição poética (Imagem 4, a seguir): 
Imagem 4: Sonho mata Orpheus
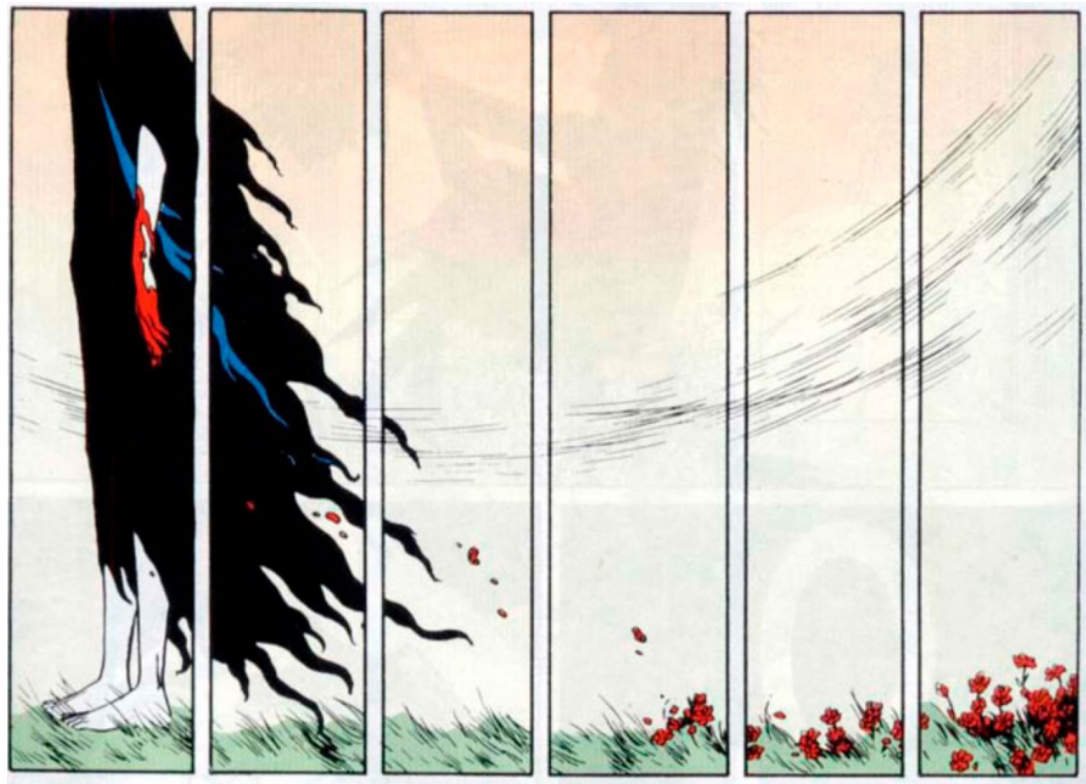

(GAIMAN, 2007, p. 224)

Como já deve ter se tornado bastante evidente a essa altura, todo o processo que envolve a busca de Sonho por Destruição é bastante simbólico: o protagonista de The Sandman não está apenas buscando um irmão desaparecido, ou um ser sobrenatural que encarna aspectos diversos daquilo que se compreende por “destruição”. Ele está procurando sua própria destruição. Daí encontrarmos, quase ao final do arco, a frase de Desespero que serve de epígrafe para nosso estudo: "Não se pode procurar Destruição e voltar ileso” (GAIMAN, 2007, p. 228).

Para o mesmo caminho aponta o encontro de Sonho com Orpheus. Essa parte específica de Brief lives remete, como já observamos, a uma releitura da mitologia grega proposta por Gaiman em sua graphic novel. Conforme essa mesma mitologia, todo crime de sangue é vingado pelas Erínias (também chamadas de "Bondosas", ou "Benevolentes"). Sonho sabe que, ao derramar o sangue do próprio filho, se tornará vítima dessas entidades. E, mais do que isso, Orpheus também possui a mesma consciência. Portanto, ao pedir ao pai que dê um fim a seus dias, Orpheus está literalmente ajudando Sonho a encontrar Destruição, sua própria destruição.

As consequências desse episódio são tão decisivas que aparecem explícitas no título do arco que contém o desfecho da narrativa: The Kindly Ones. Em português, o título foi traduzido como "Entes queridos”, o que faz perder-se a intenção original de Gaiman. The Kindly Ones é uma das expressões usadas em inglês para se fazer referência às Erínias. As correspondentes mais óbvias, em português, para que se mantivesse a referência 
às personagens mitológicas, seriam as já mencionadas “As Bondosas” ou “As Benevolentes”. E é justamente de tais personagens que tratará o arco em questão: The Kindly Ones retrata a perseguição empreendida pelas Erínias (que são chamadas pelo próprio protagonista de "Bondosas”) para vingar a morte de Orpheus pelas mãos de Sonho. Em suas páginas finais, a vingança se realiza.

Se o fato de Sonho buscar sua própria destruição em Brief lives já aponta para uma atitude, de certa forma, suicida, há uma passagem ao final de The Kindly Ones que reforça ainda mais essa impressão. Após a realização da vingança por seu crime de sangue, o personagem, ainda vivo, e ainda em seu reino, entrega seus pertences a seu corvo, Matthew, dizendo as seguintes palavras: “Tome. Leve isto para o castelo. Tenha cuidado. Minha irmã vai estar lá. Peça que venha ao meu encontro” (GAIMAN, 2008, p. 319). Poucas páginas adiante, encontramos a seguinte imagem (Imagem 5, a seguir):

Imagem 5: Morte vem ao encontro de Sonho

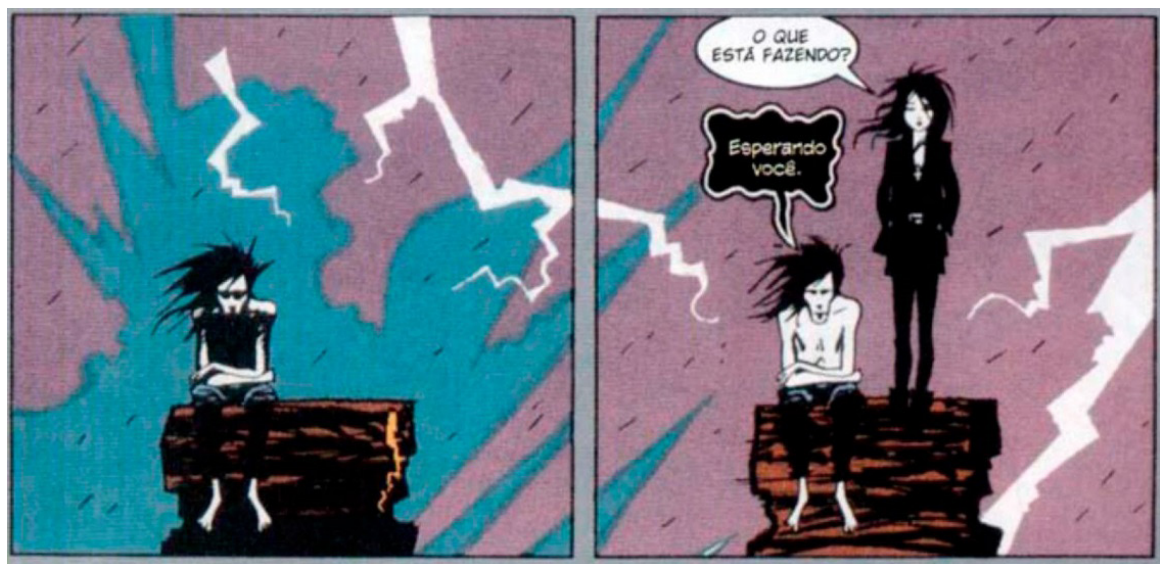

(GAIMAN, 2008, p. 323)

Ou seja: Sonho não apenas vai ao encontro da própria destruição, mas, ao final, é ele quem chama a morte para junto de si. Suas decisões e atitudes encerram, em última instância, em nível simbólico, um suicídio. Nova afirmação dessa interpretação é conferida pela seguinte fala de Morte: "Você já esteve em situações bem piores e sempre voltou. (...) O único motivo para você estar metido nessa confusão é: você queria isso” (GAIMAN, 2008, p. 327). Morte mostra-se consciente, portanto, de que a destruição de Sonho implica um processo de autodestruição: uma série de atitudes que, de um jeito ou de outro, foram planejadas.

Tendo tais reflexões em mente, e considerando a condição sobre-humana do personagem, bem como o papel decisivo de entidades pertencentes à mitologia grega no traçado de seu destino, somos incitados a pensar, em um primeiro momento, em uma concepção de suicídio que corresponda, de 
alguma forma, às perspectivas e motivações de personagens desse porte. Ao traçar um panorama sobre diversas concepções de suicídio ao longo dos tempos, na cultura ocidental, depois de arrolar uma série de ocorrências notórias do ato na Antiguidade Clássica, Alvarez chega à seguinte conclusão:

todos eles têm uma característica em comum: uma certa nobreza em seus motivos. A julgar pelos registros que deixaram, os gregos antigos só se suicidavam pelas melhores razões possíveis: por pesar, por princípios patrióticos ou para evitar a desonra (ALVAREZ, 1999, p. 71).

Sendo Sonho um ser em muitos aspectos semelhante aos deuses mitológicos, e cumprindo as Erínias um papel de primeira ordem nos eventos que levam à sua morte, parece, inicialmente, que o suicídio do personagem deveria se inscrever em uma das condições registradas por Alvarez. Mas isso não acontece. Assim como opera o deslocamento de personagens pertencentes à Grécia Antiga, trazendo-os para um contexto que carrega marcas evidentes do final do século 20, Gaiman desconstrói nossa concepção sobre os motivos que poderiam levar um ser sobre-humano a suicidar-se: as atitudes decisivas de Sonho são demasiado humanas e individuais - o que, mais uma vez, aponta para o caráter fragmentado de sua identidade.

Isso não quer dizer que a atitude do personagem seja consequência específica da desilusão amorosa (com uma humana, devemos ressaltar novamente) que ele experimentava em seus dias derradeiros: uma leitura atenta da graphic novel em sua totalidade mostra que, desde o princípio da narrativa, Sonho apresentava dificuldades em sustentar sua existência. Faltavam-lhe motivações, objetivos para seguir adiante. E é essa falta de sentido que o leva a perpetrar o aniquilamento de sua própria existência.

Longe de propor um esgotamento das possibilidades de análise de The Sandman, nosso objetivo, ao longo deste estudo, foi oferecer um aprofundamento sobre apenas algumas das muitas questões que percorrem a obra, conjugando perspectivas teóricas diversas. Recuperando o arcabouço de referências aventadas em nossas reflexões, em diálogo com os dois episódios estudados, podemos perceber o quanto a graphic novel de Gaiman reflete trabalhos teóricos que lidam com as questões do fantástico, e também aqueles que se debruçam sobre a complexa fragmentação identitária do sujeito contemporâneo. Talvez por reflexo dessa identidade cindida, que só pode ser observada a partir de pequenas peças, o protagonista da narrativa, como procuramos demonstrar, deve ser compreendido, em última instância, como um suicida. Entrelaçado ao processo de autodestruição do personagem, identificamos uma gama de referências culturais de épocas e locais variados - e tal movimento, como se compondo a figura de um ouroboros, nos lança novamente à reminiscência permanente de elementos sobrenaturais em nossas práticas cotidianas, e à miscigenação cultural tomada como objeto 
de estudo por muitos teóricos contemporâneos. Se foi possível conjugar aqui abordagens tão diversas, isso apenas mostra a pertinência de se deitar um olhar mais cuidadoso sobre The Sandman e as muitas facetas de seu mosaico composicional.

\section{Referências}

ALVAREZ, A. O deus selvagem: um estudo do suicídio. Trad. Sonia Moreira. São Paulo: Companhia das Letras, 1999.

EISNER, W. Comics \& Sequential Art. Tamarac: Poorhouse Press, 1985.

FRIEDRICH, H. Estrutura da lírica moderna (da metade do século XIX a meados do século XX). Tradução do texto de Marise M. Curioni. Tradução das poesias de Dora F. da Silva. São Paulo: Duas Cidades, 1978.

GAIMAN, N. Sandman: Vidas Breves. Tradução de Daniel Pellizzari. São Paulo: Conrad, 2007.

Sandman: Entes Queridos. Tradução de Daniel Pellizzari. São Paulo: Conrad, 2008.

HUTCHEON, L. Poética do pós-modernismo: história, teoria, ficção. Tradução de Ricardo Cruz. Rio de Janeiro: Imago, 1991.

KELLEY, B. Sequential Art, Graphic Novels, and Comics. In: SANE Journal: Sequential Art Narrative in Education, v.1, Iss. 1, p. 1-21, 2010.

PELLEGRINI, T. A narrativa brasileira contemporânea: emergência do pós-modernismo. In: Revista de Letras, PUCCAMP, n. 13, p. 48-59, dez. 1994.

ROAS, D. La amenaza de lo fantástico. In: (Org). Teorías de lo fantástico. Madrid: Arco/Libros, 2001. p. 7-44.

VILLAÇA, N. Paradoxos do pós-modernismo: sujeito e ficção. Rio de Janeiro: UFRJ, 1996.

Recebido em junho/2017.

Aceito em março/2018. 